\title{
CONTROLE AUTOMÁTICO DO FLUXO DE ÁGUA NA ETAPA DE LIMPEZA EM UNIDADES DE BENEFICIAMENTO DE TOMATE DE MESA
}

\author{
MARCOS D. FERREIRA ${ }^{1}$, RAFAEL P. BENICIO ${ }^{2}$, CLÁUDIO K. UMEZU ${ }^{3}$
}

\begin{abstract}
RESUMO: A água é um recurso cada vez mais escasso e também de alto custo em várias regiões. $\mathrm{O}$ beneficiamento de frutas e hortaliças, em geral, apresenta elevado consumo de água durante $\mathrm{o}$ processo de limpeza. A linha de beneficiamento e de classificação do tomate de mesa é constituída de: recebimento, limpeza, seleção, classificação e embalagem. Normalmente, o recebimento dos tomates em uma linha de beneficiamento ocorre com taxa de alimentação constante, porém com interrupções frequentes dos operadores, ocasionando desperdício de energia e água, e a eficiência de limpeza dos frutos. O objetivo deste trabalho foi avaliar um sistema de limpeza dos frutos, equipado com um controle automático de fluxo de água, visando ao uso racional de água. Para a avaliação da eficiência do processo de limpeza, aplicou-se uma metodologia que utiliza o turbidímetro. Observou-se que o índice de limpeza foi, segundo critérios estatísticos, semelhante nos sistemas automatizado e tradicional, todavia o consumo de água no sistema automatizado foi quatro vezes inferior quando comparado ao sistema tradicional, indicando o potencial de aplicação comercial deste sistema.
\end{abstract}

PALAVRAS-CHAVE: CLP, limpeza, água, Lycopersicon esculentum Mill.

\section{AUTOMATIC CONTROL OF WATER SISTEMS IN THE CLEANING STEP IN FRESH MARKET TOMATO PACKING UNITS}

\begin{abstract}
Water is a natural resource becoming scarce in many regions. Cleaning fruits and vegetables, generally demands high water consumption. A fresh market tomato packing-line is composed of: receiving, cleaning, sorting, classifying and packing. Normally, the receiving process for tomatoes in a packing line happens in a constant flow, however often interruptions of operators cause loss of water, energy and also fruits cleaning efficiency. The main goal of this study was to develop an automation system for cleaning fruits, with a rational water use. For evaluating cleaning efficiency it was developed a methodology using a turbidimiter. The results showed that the cleaning efficiency index was statistically similar between the two systems; however, water consumption for the automated system was four times lower than the traditional system, suggesting a potential for commercial application on this system.
\end{abstract}

KEYWORDS: controller, efficiency, water, Lycopersicon esculentum Mill.

\section{INTRODUÇÃO}

A cultura do tomateiro foi introduzida no Brasil pelos imigrantes italianos, mas desenvolveuse para consumo in natura com a vinda dos imigrantes japoneses (FONSECA \& MILANI, 1982). Com um clima favorável e com amplo espaço físico para seu cultivo, o Brasil, em 2007, foi o $9^{\circ}$ produtor mundial de tomate, com uma produção de 3,3 milhões de toneladas, cultivadas em uma área de 56,68 mil hectares (FAO, 2008). O Estado de Goiás foi o maior produtor em 2007, com 802.128 toneladas, seguido por São Paulo, com 713.483 toneladas (IBGE, 2008). Todavia, o Brasil exporta muito pouco tomate, apenas $0,06 \%$ de sua produção (FNP CONSULTORIA E COMÉRCIO, 2006). Assim, o seu maior consumidor é o mercado interno, que se tornou mais

\footnotetext{
${ }^{1}$ Doutor, Pesquisador Embrapa Instrumentação, São Carlos, SP, e professor; colaborador Faculdade de Engenharia Agrícola/Unicamp, Campinas, SP. E-mail: marcos.ferreira@cnpdia.embrapa.br.

${ }^{2}$ Eng. Agrícola. Faculdade de Engenharia Agrícola/Unicamp, Campinas, SP. E-mail: rafael.benicio@ feagri.unicamp.br.

${ }^{3}$ Doutor, Pesquisador, Faculdade de Engenharia Agrícola/Unicamp, Campinas, SP. E-mail: umezu@ feagri.unicamp.br.

Recebido pelo Conselho Editorial em: 10-6-2009

Aprovado pelo Conselho Editorial em: 27-5-2011
} 
competitivo e exigente, sendo necessários investimentos na área de beneficiamento e classificação, para obtenção de um produto de melhor qualidade.

Várias modificações têm ocorrido nos últimos anos, no beneficiamento do tomate de mesa, com a introdução de equipamentos para benefício e classificação em unidades de beneficiamento, diferentemente do que ocorria anteriormente, quando todo tomate era classificado e embalado no campo, manualmente. Produtores de tomate para mesa investiram em máquinas especiais de seleção e classificação, importadas e nacionais, e na montagem de unidades de beneficiamento, tornando-se, portanto, atacadistas/distribuidores deste produto ao adquirirem também a produção de outros produtores (FNP CONSULTORIA E COMÉRCIO, 2000). MARCOS (2001) afirmou que os consumidores relacionam o grau de sujidade dos frutos com sua qualidade. Assim, quanto menor a sujidade dos produtos, maior a aceitação do consumidor, o que torna a etapa de limpeza essencial no sistema de beneficiamento.

FERREIRA et al. (2005) descrevem que existe grande variação entre as unidades de beneficiamento de tomates em função do tipo de equipamento (nacional ou importado), número e rotações das escovas, comprimento da linha, etc. Esses fatores influenciam no custo final do equipamento e em sua eficiência de funcionamento. A etapa de limpeza é importante, pois consiste na remoção de partículas de solo e/ou outros materiais estranhos da superfície das frutas e hortaliças (FERREIRA \& MAGALHÃES, 2008; SIGRIST et al., 2002), e deve ser realizada antes de o produto ser embalado para a comercialização (PELEG, 1985). Durante o processo de lavagem, os frutos passam por uma série de escovas rotativas que transportam e friccionam os frutos, os quais são submetidos a jatos de água constantes (FERREIRA \& MAGALHÃES, 2008).

Todavia, o uso da água deve ser racional, pois a disponibilidade de água transformou-se, nos últimos anos, em um problema mundial. Mesmo em países onde há fartura de água, como é o caso do Brasil, já existem regiões onde a disponibilidade já está comprometida pelo aumento populacional desordenado e pela necessidade de acréscimo na produção de alimentos (COLETTI, 2005). PATERNIANI (2007) relata que o Brasil ocupa o primeiro lugar dentre os países com maior quantidade de água, situação que influencia na cultura do desperdício, falta de investimentos na preservação e em planos de gestão dos recursos hídricos.

SILVA et al. $(2006,2008)$ estimaram um excessivo gasto de água durante o processo de lavagem de tomate de mesa, em especial para o sistema convencional, que é constituído de tubos de PVC com orifícios perfurados. Estes autores verificaram que alternativas com o uso do sistema com bicos tipo spray reduzem a quantidade de água com aumento na eficiência de limpeza. FERREIRA \& NETTO (2007) também relatam um gasto excessivo de água durante o processo de lavagem da batata para a retirada de toda a terra agregada ao tubérculo, o qual varia de 15.400 a 168.000 litros por hora trabalhada, dependendo do tipo de sistema utilizado para lavagem dos tubérculos. Segundo FERREIRA \& MAGALHÃES (2008), a eficiência da limpeza pode ser obtida com menores quantidades de água, quando associadas, por exemplo, a uma escovação efetiva. Entretanto, a etapa de lavagem nas atuais unidades de beneficiamento caracteriza-se por não ter controle preciso da quantidade de água utilizada na limpeza e a falta de precauções técnicas com o descarte da água, que, após o uso, é geralmente despejada em córregos e mananciais, trazendo sérias preocupações ambientais. Portanto, é necessário buscar alternativas ao sistema de lavagem, de modo que a utilização da água no sistema de beneficiamento seja mais racional.

Tem-se observado recentemente a utilização de equipamentos importados com automação para beneficiamento de tomate de mesa. A automação é um processo de evolução tecnológica irreversível, com várias vantagens, destacando-se a rapidez e a precisão na execução de tarefas e no aumento da produtividade, proporcionando conseqüentemente uma redução nos custos de produção (SILVEIRA \& SANTOS, 1998). Todavia, em unidades de beneficiamento, a automação é mais usada para o sistema de classificação, tanto para diâmetro, quanto para coloração do fruto (FERRARI, 2006). 
Este trabalho teve como objetivo avaliar o uso de um sistema automático de controle do fluxo de água como alternativa para a redução no consumo de água, na etapa de limpeza de tomate de mesa.

\section{MATERIAL E MÉTODOS}

O trabalho foi dividido em duas etapas. Na primeira, desenvolveu-se um sistema automático no processo de aplicação de água e, em uma segunda etapa, foram realizados testes para a determinação do consumo de água e verificação da eficiência da limpeza nos dois sistemas.

\section{Primeira etapa - Desenvolvimento do sistema automático de aplicação de água}

A automação do fluxo de água para lavagem dos frutos baseia-se na detecção da presença de frutos e o seu acionamento no momento adequado, e pelo tempo necessário para a limpeza dos frutos.

Inicialmente, foi necessário determinar o tempo de permanência dos frutos sob o jato de água. Para isso, frutos de tomates foram despejados no início do processo e realizou-se a mensuração do tempo transcorrido na etapa de lavagem por meio de um cronômetro de precisão. A determinação deste tempo foi fundamental para o desenvolvimento do sistema, pois, no momento da interrupção do fornecimento da água, nenhum fruto pode estar na etapa de lavagem.

$\mathrm{Na}$ entrada dos frutos na etapa de lavagem, foi colocado um sensor de presença óptico infravermelho, do tipo reflexão, marca Instrutech, com alimentação de $24 \mathrm{Vdc}$ e saída do tipo PNP. Neste sensor, os elementos de emissão e recepção estão justapostos no mesmo conjunto óptico, e os raios emitidos pelo transmissor são refletidos em um espelho prismático colocado à sua frente $\mathrm{e}$ retornam ao elemento receptor. Na existência de um objeto, o feixe é interrompido, e um sinal elétrico é gerado pelo sensor. Na Figura 1, apresentam-se os posicionamentos do sensor óptico e do espelho prismático no protótipo de limpeza, cuja localização possibilita detecção da presença de frutos que ainda não iniciaram o processo de lavagem.

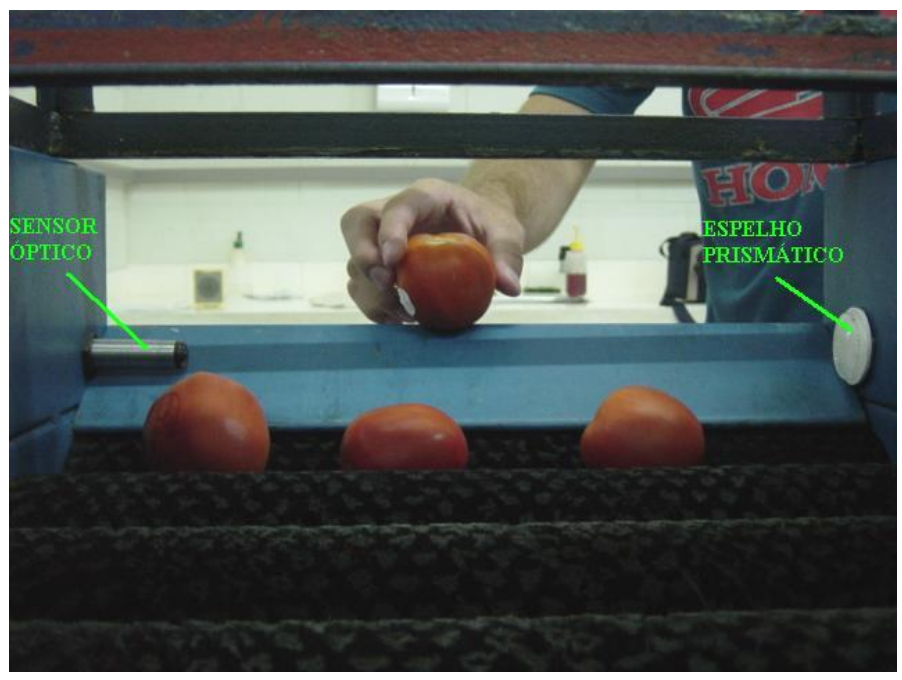

FIGURA 1. Sensor óptico e espelho prismático instalados no protótipo de limpeza. Optical sensor and prism mirror installed in the prototype.

Para a automação do processo de aplicação de água, utilizou-se um Controlador Lógico Programável (CLP) da marca HI Tecnologia, modelo ZAP 500, equipado com 6 entradas e 4 saídas digitais. Em uma das entradas digitais do CLP, conectou-se o sensor óptico, que envia sinais digitais, na forma de tensão para o controlador, acusando a presença ou não de frutos na etapa de lavagem. Inicialmente, propôs-se o acionamento de válvulas solenoides, que permaneceriam abertas durante um tempo predeterminado. Com o intuito de simplificar o desenvolvimento, utilizou-se um 
inversor de frequência (marca WEG, modelo CFW 08), que aciona diretamente a bomba hidráulica, dispensando o uso de válvulas solenoides. O uso de um inversor de frequência permitiu o acionamento de forma suave da bomba, evitando trancos decorrentes da partida do motor elétrico.

O sistema hidráulico é composto por uma bomba (1,0 HP, marca KSB) acoplada a um reservatório de água, que pressuriza a água ao bico aspersor (fabricado por Spray Systems, modelo Quick Full Jet-ProMax, QPHA-1.5), que propicia um jato do tipo cone cheio. Na Figura 2, mostra-se uma visão geral do sistema e dos equipamentos utilizados para o funcionamento e avaliação do mesmo.

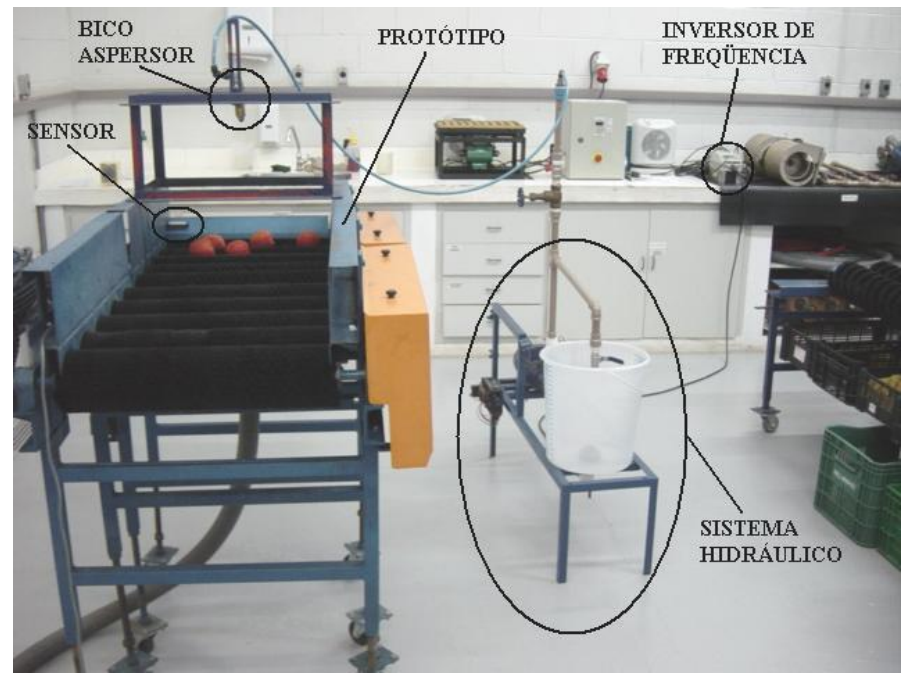

FIGURA 2. Equipamentos utilizados no experimento: protótipo, sistema hidráulico, inversor de frequência, bico aspersor e sensor óptico. Equipments used in the experiment: prototype, hydraulic system, frequency invertor, spray nozzle and optical sensor.

Para o desenvolvimento do aplicativo de controle, o CLP foi conectado a um computador e, através do ambiente de desenvolvimento SPDSW (fornecido pelo fabricante), desenvolveu-se o aplicativo, em linguagem Ladder. A Figura 3 apresenta o fluxograma do aplicativo do controle automático do fluxo de água de limpeza.

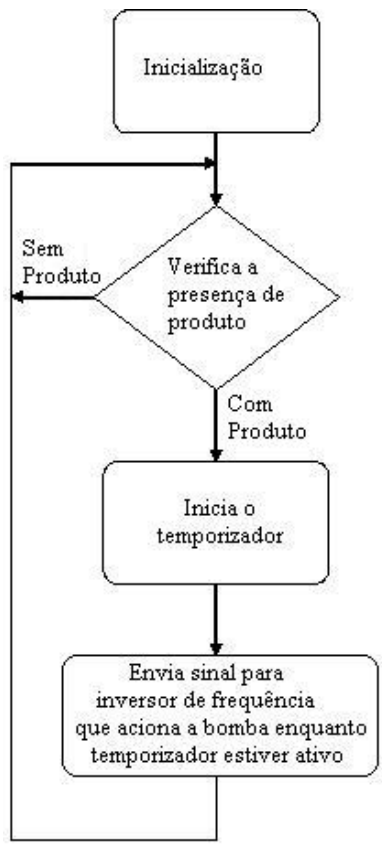

FIGURA 3. Fluxograma do aplicativo para controle automático do fluxo de água de limpeza. Flowchart for automatic control application of the cleaning water flow. 
Após a detecção da presença de frutos na etapa de limpeza, inicia-se o processo de lavagem através do acionamento da bomba. Uma rotina de temporização determina por quanto tempo o bico aspersor ficará operante após a detecção de um fruto. Sempre que houver a detecção de um novo fruto na entrada do protótipo, esse temporizador é zerado.

O valor da temporização pode ser ajustado pelo operador através da Interface HomemMáquina (IHM), existente no controlador. Acrescentou-se também uma rotina que permite o armazenamento da quantidade de vezes que o sistema de lavagem é acionado e qual o tempo total que ele permaneceu ligado. Esses valores foram utilizados para se estimar a quantidade total de água aplicada no processo.

\section{Segunda etapa - Determinação do consumo de água e verificação da eficiência de limpeza no sistema tradicional e automatizado}

Nessa etapa, foram utilizadas 25 esferas de borracha com $70 \mathrm{~mm}$ de diâmetro e 230 gramas, para simular frutos de tomate. As esferas foram impregnadas com uma substância denominada "sujeira artificial", preparada por meio da homogeneização de $20 \mathrm{ml}$ de polietileno de alta densidade, com concentração de 22,7\% (Meghwax EPE 350N - Megh), $20 \mathrm{ml}$ de têmpera de guache preta (Acrilex) e 6 gramas de carvão vegetal moído e peneirado, Tyler Mesh 48 (FRANCO et al., 2005).

Para a aplicação da sujeira, cada esfera foi apoiada em um béquer de $200 \mathrm{ml}$ e realizou-se a aplicação da sujeira, primeiramente, em um lado da esfera, aguardando-se 30 minutos para a secagem e só então se aplicou a sujeira do outro lado, aguardando-se mais 30 minutos para a finalização do processo. A aplicação foi de apenas uma demão e com o auxílio de um pincel.

Para mensurar a quantidade de sujeira aplicada em cada ensaio, a massa das esferas foi aferida antes e após a aplicação da sujeira, por meio de uma balança digital (marca Marte Balanças e Aparelhos de Precisão, modelo AL500C), com capacidade máxima de $500 \mathrm{~g}$ e precisão de $0,01 \mathrm{~g}$. A massa de sujeira ( $\mathrm{g}$ ) foi obtida pela diferença entre a massa inicial da esfera e a massa da esfera com a sujeira (MAGALHÃES, 2007).

As esferas foram então submetidas ao processo de limpeza em dois tratamentos:

Tratamento 1 - Lavagem das esferas em sistema contínuo (tradicional);

Tratamento 2 - Lavagem das esferas utilizando-se do sistema automatizado.

Em ambos os sistemas, as esferas foram colocadas de forma aleatória no início do processo de limpeza, em intervalos de alimentação de 30; 60 e 90 segundos, simulando uma operação real, baseada em dados coletados em campo (FRANCO et al., 2007). Para cada ensaio, foram realizadas três repetições. A quantidade de água consumida no sistema tradicional e no sistema automatizado foi coletada por um tanque posicionado na parte inferior do equipamento e mensurada por uma proveta graduada de $500 \mathrm{~mL}$.

Para a verificação da eficiência de ambos os processos, após passarem pela etapa de limpeza, as esferas de borracha foram lavadas, individualmente e manualmente, com $250 \mathrm{~mL}$ de água destilada. Em seguida, coletaram-se $20 \mathrm{~mL}$ da água de limpeza (água misturada com resíduos) e mediu-se a turbidez da amostra em NTU, por meio de um turbidímetro de bancada microprocessado (marca MS Tecnopon Instrumentação Científica, modelo TB 1.000).

Um índice de sujeira foi determinado por meio da análise de turbidez de 10 esferas totalmente sujas, que não passaram pelo protótipo. As etapas da metodologia aplicada para avaliação da eficiência de limpeza, pelo método do turbidímetro são apresentadas na Figura 4. 


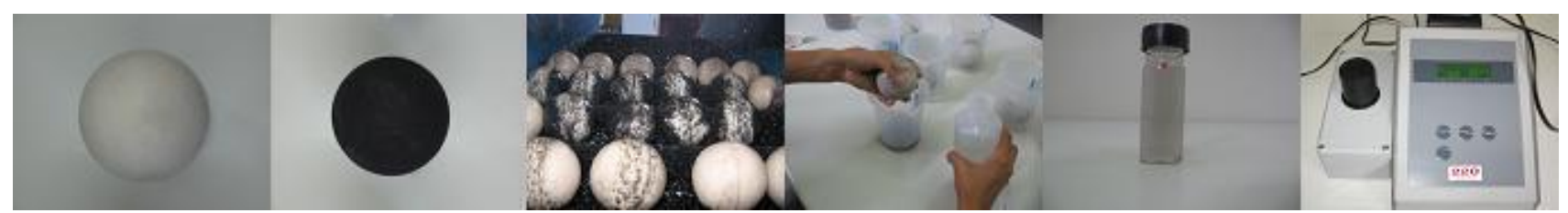

FIGURA 4. Etapas para a determinação do índice de limpeza: esfera limpa, esfera suja, esferas no protótipo, lavagem manual/individual das esferas após a passarem pelo protótipo, amostra da água de limpeza e turbidímetro de bancada. Steps for determining cleaning efficiency: clean sphere, dirty sphere, spheres on the prototype, hand washing / personal spheres after passing through prototype, cleaning water sample and bench turbidimeter.

Os resultados foram dados em função do índice de limpeza descrito na Equação 1.

$$
\mathrm{IL}=\left(\frac{\mathrm{NTU}_{\text {padrão }}-\mathrm{NTU}_{\text {amostra }}}{\mathrm{NTU}_{\text {padrão }}}\right) 100
$$

em que,

IL - índice de limpeza, \%;

NTU padrão - 93,66; valor médio determinado como referência para esferas totalmente sujas, e

NTU amostra - número de turbidez de cada amostra.

O delineamento estatístico foi o inteiramente casualizado, com esquema fatorial 2 x 3 (dois sistemas de limpeza e três intervalos de descarregamento), totalizando 6 tratamentos, com 3 repetições. Para avaliar se houve diferença estatística entre os índices de limpeza, utilizaram-se a análise de variância e o teste de Tukey a 95\%, para a comparação das médias.

\section{RESULTADOS E DISCUSSÃO}

Os testes comparativos foram realizados na segunda etapa, e foi observado que, com o aumento do tempo de descarregamento de 30 para 90 segundos, o sistema de lavagem tradicional apresentou um consumo de água crescente, de 555 a $1.545 \mathrm{~mL}$. Todavia, com o sistema automático, o consumo de água foi praticamente constante, com valores entre 325 e 375 mL (Figura 5). Com o aumento do intervalo de descarregamento, a quantidade de água requerida pelo sistema de lavagem tradicional é muito elevada, chegando a ser 4,12 vezes maior que o sistema automatizado.

FRANCO et al. (2007) relatam que o consumo de água em unidades de beneficiamento para tomate de mesa, mesmo utilizando bico spray, pode chegar acerca de 1.000 litros de água por hora. ROGER (2008) considera que a agricultura é a grande responsável pelo consumo de água, e que intervenções devem ser realizadas visando à redução e à racionalização no uso, já que o gasto diário de água de uma pessoa, considerando beber, higiene e alimentos para consumo, é próximo de 3.000 litros. Portanto, a utilização de automação no sistema de lavagem pode em muito contribuir para a economia de água para diversas culturas. 


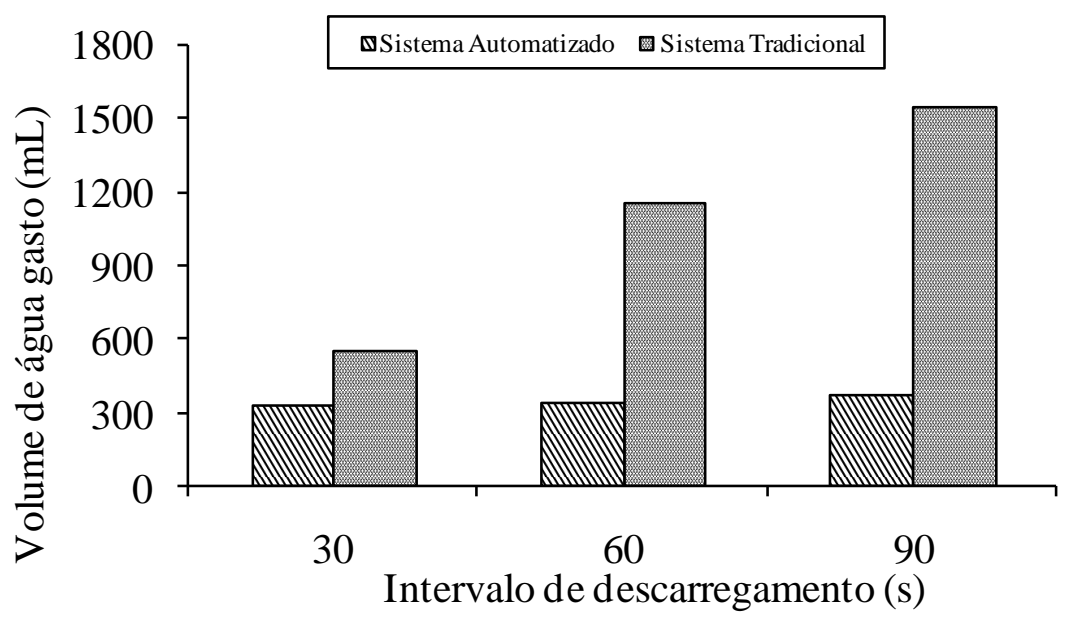

FIGURA 5. Volume de água utilizado no sistema automatizado e sistema tradicional, para os três intervalos de descarregamento. Water volume used in the automated and traditional system, for three ranges of unloading.

Aplicando-se, o teste de Tukey, observou-se que houve diferença significativa, em nível de 95\%, no índice de limpeza, entre os sistemas automatizado e tradicional, para os intervalos de descarregamento de 30 e $60 \mathrm{~s}$. Nestes dois tempos, o índice de limpeza no sistema tradicional foi, próximo de $90,0 \%$, enquanto com o sistema automático esse índice foi de $86,2 \%$ para um intervalo de descarregamento de $30 \mathrm{~s}$, e 87,8\% para $60 \mathrm{~s}$. Para um intervalo de descarregamento de $90 \mathrm{~s}$, o índice de limpeza foi maior para o sistema automático, com um valor médio de $90,7 \%$, enquanto o sistema tradicional apresentou um índice de limpeza de 88,5\% (Figura 6).

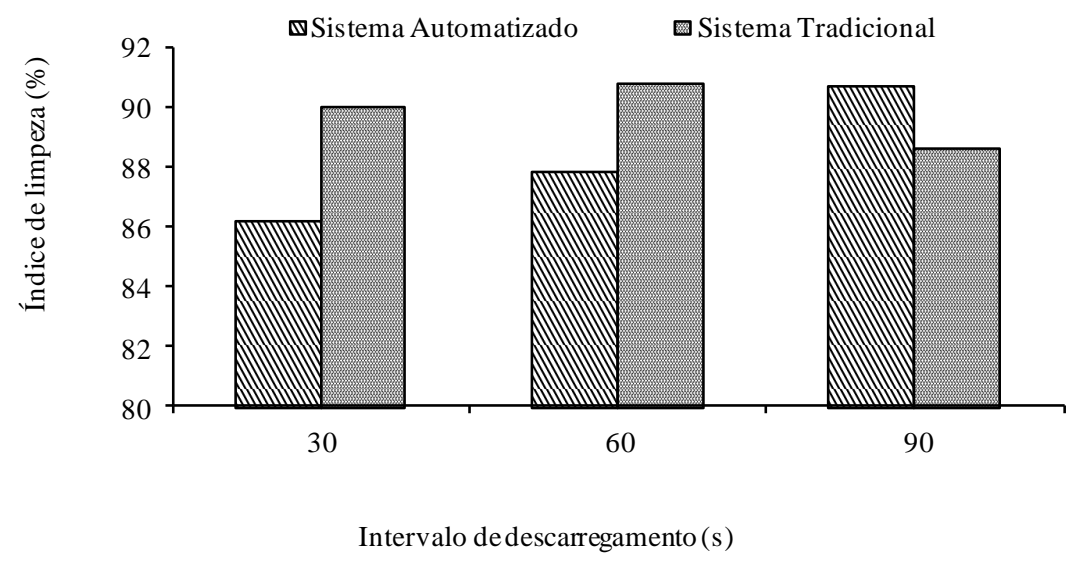

FIGURA 6. Índice de limpeza médio obtido para as 25 esferas submetidas à limpeza no protótipo com sistema de aplicação de água automatizado e tradicional para os três intervalos de descarregamento. Average cleaning efficiency obtained from 25 spheres submitted to cleaning in the prototype using automated and traditional water system on three ranges of unloading.

O uso de um sistema automático reduziu significativamente a quantidade de água aplicada na limpeza do tomate de mesa, garantindo uma eficiência desta operação, limpeza superior ao sistema tradicional, para o descarregamento em $90 \mathrm{~s}$, e um índice de limpeza um pouco inferior nos outros dois tempos de descarregamento. Para FALKENBERG (2005), o uso da automação nos sistemas de abastecimento de água aperfeiçoou as operações, para o melhoramento contínuo dos serviços de captação, tratamento e distribuição de água, e redução de custos relacionados, tais como energia, produtos químicos e perdas físicas de água (vazamentos). 


\section{CONCLUSÕES}

Os resultados demonstram o potencial de uso de um sistema automatizado para controle da aplicação de água em uma linha de beneficiamento de frutas e hortaliças, com redução considerável no consumo de água e manutenção da eficiência de limpeza. O sistema desenvolvido pode ser facilmente adaptado a equipamentos de limpeza comerciais, novos e usados. $\mathrm{O}$ custo da implantação do sistema pode ser amortizado pela economia de água obtida. Estudos futuros devem ser realizados propondo outras alterações no equipamento com o maior aumento da eficiência de limpeza.

\section{AGRADECIMENTOS}

Ao sistema PIBIC/SAE da Universidade Estadual de Campinas, pela bolsa de iniciação científica; à Fundação de Amparo à Pesquisa do Estado de São Paulo (02-00645-7) e ao PRODETAB/EMBRAPA (055/02-01), pelo apoio financeiro.

\section{REFERÊNCIAS}

AGRIANUAL 2001: anuário da agricultura brasileira: São Paulo, FNP Consultoria e Comércio, $2000.516 \mathrm{p}$

AGRIANUAL 2007: anuário da agricultura brasileira: São Paulo, FNP Consultoria e Comércio, 2006. $516 \mathrm{p}$

COLETTI, C. Caracterização da irrigação por sulcos na cultura do tomateiro e da disponibilidade hídrica da Bacia Hidrográfica do Rio das Pedras-SP. 2005. 173 f. Tese (Doutorado) - Universidade Estadual de Campinas, Campinas, 2005.

FALKENBERG, A.V. Previsão de consumo urbano de água em curto prazo. $2005.89 \mathrm{f}$. Dissertação (Mestrado) - Universidade Federal do Paraná, Curitiba, 2005.

FAO. Faostat agriculture data. Disponível em: <http://faostat.fao.org>. Acesso em: 18 jul. 2008.

FERRARI, P.R. Avaliação da qualidade da classificação do tomate de mesa. 2006. 147 p.

Dissertação (Mestrado).

FERREIRA, M.D.; KUMAKAWA, M.K.; ANDREUCCETTI, C.; HONÓRIO, S.L.; TAVARES, M.; MATHIAS, M.L. Evaluation of packing lines and classification standards for fresh market tomatoes in Brazil. Horticultura Brasileira, Brasília, v.23, n.4, p.940-944, 2005.

FERREIRA, M.D.; MAGALHÃES, A.M. Avaliação da etapa de limpeza em sistemas de beneficiamento e classificação. In: FERREIRA, M.D. (Editor). Colheita e beneficiamento de frutas $e$ hortaliças. São Carlos: Embrapa Instrumentação Agropecuária, 2008. p.63-68.

FERREIRA, M.D.; NETTO, L.H. Avaliação de processos nas linhas de beneficiamento e classificação de batatas. Horticultura Brasileira, Brasília, v.25, n.2, p.279-285, 2007.

FONSECA, H.; MINAMI, K. Tomate: produção, pré-processamento e transformação agroindustrial. Hamburg, 1982. (Série Extensão Agroindustrial, 8)

FRANCO, A.T.O.; FERREIRA, M.D., FERRAZ. A.C.O. Avaliação do processo de limpeza em protótipo do sistema UNIMAC. In: CONGRESSO BRASILEIRO DE ENGENHARIA AGRÍCOLA, 34., 2005, Canoas. Resumos ... Canoas: SBEA, 2005. 1 CD-ROM.

FRANCO, A.T.O.; FERREIRA, M.D.; MAGALHÃES, A. M.; FERRAZ. A.C.O.; TAVARES, M. Caracterização de dois equipamentos de beneficiamento e classificação de tomates de mesa. Engenharia Agrícola, Jaboticabal, v.27 n.3, p.787-793, 2007.

IBGE. INSTITUTO BRASILEIRO DE GEOGRAFIA E ESTATÍSTICA. Banco de dados agregados. Disponíver em: 〈http://www.sidra.ibge.gov.br/>. Acesso em: 12 jul. 2008. 
MAGALHÃES, A.M. Eficiência de limpeza durante o beneficiamento do tomate de mesa. 2007. 107 f. Dissertação (Mestrado) - Faculdade de Engenharia Agrícola, Universidade Estadual de Campinas, Campinas, 2007.

MARCOS, S.K. Desenvolvimento de tomate de mesa, com o uso do método Q. F. D. Quality Function Deployment comercializado em um supermercado. 2001. $200 \mathrm{f}$. Tese (Doutorado) Universidade Estadual de Campinas, Campinas, 2001.

PATERNIANI, J.E.S. Disponibilidade hídrica. NetaNews, v.4, n.19, p.4, 2007.

PELEG, K. Produce handling, packing and distribution. Westport: AVI Publishing, 1985. 625 p.

ROGER, P. Preparando-se para enfrentar a crise da água. Scientific American Brasil, p.60-67, 2008.

SIGRIST, J.M.M.; BLEINROTH, E.W.; MORETTI, C.L. Manuseio pós-colheita de frutas e hortaliças. In: CORTEZ, L.A.B; HONÓRIO, S.L.; MORETTI, C.L. Resfriamento de frutas e hortaliças. Brasília: Embrapa Hortaliças, 2002. 428 p.

SILVA, M.C.; TESTEZLAF, R.; FERREIRA, M. D. Washing mechanism improvements for fresh market tomatoes cleaning equipment. Engenharia Agrícola, Jaboticabal, v.26, n.2, p.637-643, 2006.

SILVA, M.C.; FRANCO, A.T.O.; FERREIRA, M.D.; MAGALHÃES, A.M.; TESTEZLAF, R. Otimização da eficiência de limpeza em equipamento de beneficiamento de tomate de mesa. Engenharia Agrícola, Jaboticabal, v.28, n.4, p.750-758, 2008.

SILVEIRA, P.R.; SANTOS, W.E. Automação e controle discreto. 4.ed. São Paulo: Ética, 1998. 229 p. 